\title{
Erratum: Non-negative Matrix Factorization with Orthogonality Constraints and its Application to Raman Spectroscopy
}

\author{
HUALIANG LI, TÜLAY ADALI AND WEI WANG \\ Department of CSEE, University of Maryland Baltimore County, Baltimore, MD, USA \\ DARREN EMGE \\ US Army Research, Aberdeen Proving Grounds, Aberdeen, MD 21010, USA \\ ANDRZEJ CICHOCKI \\ Laboratory for Advanced Brain Signal Processing, Brain Science Institute, \\ Riken 2-1 Hirosawa, Wako-shi, Saitama 351-0198, Japan \\ ANDRZEJ CICHOCKI \\ Warsaw University of Technology, Warsaw, Poland
}

The HTML author list of this original article includes the incorrect spelling of Tülay Adali's name. It appears correctly here. This was a typesetter error. 